\title{
SISTEM INFORMASI JURNAL ELEKTRONIK BERBASIS WEB PADA UNIVERSITAS DIPONEGORO
}

\author{
Rafly Anditya Mukti 1), Eko Didik Widianto ${ }^{2)}$, Dania Eridani ${ }^{3)}$ \\ 1,2,3 Departemen Teknik Komputer, Universitas Diponegoro \\ 1,2,3 Jalan Prof. Soedarto, S.H., Tembalang, Semarang, Indonesia \\ Email: ramukti@student.ce.undip.ac.id
}

\begin{abstract}
In this modern era, a university is certainly required to have a healthy research and research climate. One indicator of a healthy research climate is the number of journals that regularly publish scientific articles. The main problem with the many journals published in universities is the manual management and data collection of journals. Therefore, a journal management information system that is able to organize, collect, and provide journal statistical data is needed. The system development method used in this research is the Waterfall method which consists of system analysis, system design, system implementation, and testing. This system is also built using the CodeIgniter framework and MySQL database, plus Microsoft Azure as the hosting and system domain. This research is able to produce a system capable of storing, sorting, and printing journal data as well as recording journal accreditations. The resulting system has gone through blackbox testing where all functions have gone well. This system has also been tested for its performance and is declared good in terms of server response speed and content connectivity with the web server, where of the 27 pages that have been tested, only 1 page got a $C$ score.
\end{abstract}

Keywords: Journal Information System; Waterfall; Accreditation; MySQL; CodeIgniter

\begin{abstract}
Abstrak
Pada era modern ini, sebuah perguruan tinggi tentunya diharuskan memiliki iklim riset dan penelitian yang sehat. Salah satu indikator iklim riset yang sehat adalah dengan banyaknya jurnal yang secara berkala menerbitkan artikel-artikel ilmiah. Permasalahan utama dari banyaknya jurnal yang terbit pada perguruan tinggi adalah pengelolaan dan pendataan jurnal yang dilakukan secara manual. Oleh karena itu, dibutuhkan sistem informasi pengelolaan jurnal yang mampu mengorganisir, menghimpun, dan menyediakan data statistik jurnal. Metode pengembangan sistem yang digunakan dalam penelitian ini adalah metode Waterfall yang terdiri dari analisa sistem, desain sistem, implementasi sistem, dan pengujian. Sistem ini juga dibangun dengan menggunakan kerangka kerja CodeIgniter dan basis data MySQL, ditambah Microsoft Azure sebagai hosting dan domain sistem. Penelitian ini mampu menghasilkan sebuah sistem yang mampu menyimpan, menyortir, dan mencetak data jurnal sekaligus mencatat akreditasi jurnal. Sistem yang dihasilkan sudah melalui pengujian blackbox dimana semua fungsi telah berjalan dengan baik. Sistem ini juga duji performanya dan dinyatakan baik dilihat dari kecepatan respon server dan konektivitas konten dengan web server, dimana dari 27 halaman yang telah diuji, hanya 1 halaman yang mendapat skor $\mathrm{C}$.
\end{abstract}

Kata Kunci: Sistem Informasi Jurnal; Waterfall; Akreditasi;MySQL; CodeIgniter

\section{Pendahuluan}

Universitas Diponegoro merupakan salah satu perguruan tinggi terbaik di Indonesia yang telah menerapkan dan memiliki sistem yang mengikuti perkembangan dunia teknologi, seperti sistem informasi akademik online, krs online, absensi sidik jari, dan masih banyak lagi. Namun, dalam aspek penyediaan dan penghimpunan informasi jurnal beserta kelengkapannya sebagai pendukung iklim penelitian bagi dosen dan ahli di lingkup kampus, Universitas Diponegoro masih melakukannya secara manual, pendataan masih dilakukan menggunakan tabel pada software Microsoft excel, padahal penyediaan dan penghimpunan informasi jurnal terutama secara elektronik merupakan hal yang sangat penting.
Oleh karena itu, perlu dibuat sebuah sistem informasi jurnal elektronik untuk menyelesaikan permasalahan tersebut. Diharapkan dengan dikembangkannya sistem informasi jurnal elektronik ini, dapat memudahkan upaya pendataan jurnal ilmiah di Universitas Diponegoro dan lingkungan sekitarnya serta membantu dalam pemantauan, perincian dan pengelompokan jurnal sehingga nantinya dapat menjadi acuan peningkatan kualitas jurnal yang ada di lingkungan kampus.

Dalam melakukan penelitian mengenai pembuatan sistem informasi jurnal elektronik berbasis web ini mengambil beberapa referensi dari penelitianpenelitian sebelumnya tentang sistem informasi. Beberapa poin yang diambil diantaranya pada penelitian tentang perancangan dan implementasi e-jurnal pada 
stmik prabumulih, pengelolaan jurnal dalam bentuk online/elektronik ini menggunakan sebuah sistem yang mampu memudahkan UP2M mempublikasikan jurnal yang dirancang menggunakan metode prototyping ${ }^{[1]}$, kemudian pada artikel "Pengembangan Sistem Informasi Manajemen Pengelolaan Dan Penerbitan Jurnal Ilmiah

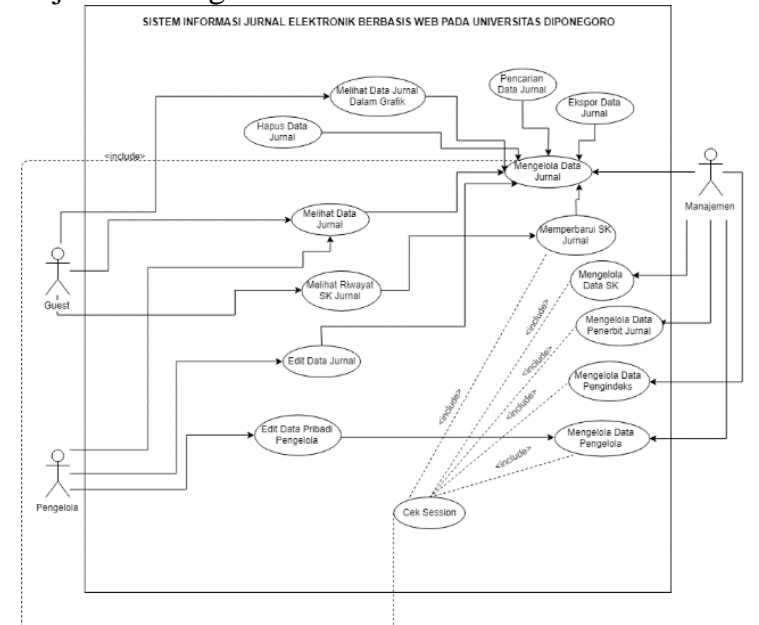

Jurusan Akuntansi Program S1" sistem berhasil membuat sebuah prosedur standar pengelolaan jurnal yang terstruktur dan kronologis ${ }^{[2]}$, lalu pada penelitian menggunakan kerangka kerja CodeIgniter "Sistem Informasi Penjadwalan Dokter Berbasis Web Dengan Menggunakan Framework Codeigniter (Studi Kasus: Rumah Sakit Yukum Medical Centre)." [3] CodeIgniter disini mampu menyelesaikan masalah kompleks penjadwalan dokter.

Penelitian lain yang menjadi rujukan kajian dan perbandingan untuk membangun sistem informasi ini, diantaranya sistem informasi inventarisasi sekolah ${ }^{[4]}$, sistem informasi data alumni ${ }^{[5]}$, sistem informasi kepegawaian pada PT Sederhana Karya ${ }^{[6]}$, sistem informasi data guru MDTA ${ }^{[7]}$, sistem informasi trainee dan daily worker untuk industry pariwisata Bali [8] , sistem informasi pendataan siswa SMP Darul Yatama ${ }^{[9]}$, dan sistem informasi persediaan barang karoseri di PT Putera Agung Setia ${ }^{[10]}$.

Penelitian-penelitian yang menjadi referensi tersebut, dinilai memiliki fitur-fitur dan kebutuhan sejenis untuk menjadi dasar perancangan sistem informasi jurnal elektronik. Sistem yang dibangun samasama memiliki kemampuan untuk menampilkan data profil secara komprehensif dan memiliki kemampuan olah data melalui grafik serta kemampuan untuk memperbarui sebuah data yang sangat spesifik.

Berdasarkan referensi penelitian sebelumnya, maka melalui penelitian ini akan dibangun sistem informasi jurnal elekronik berbasis web yang mampu memberi informasi umum jurnal, seperti jurnal yang telah terakreditasi, jurnal berbahasa inggris, jurnal yang memiliki ISSN, tahun mulai jurnal, penerbit jurnal, ketua editor jurnal, frekuensi terbit jurnal dalam satu tahun serta indeksasi jurnal. Disamping informasi tersebut, sistem ini juga mempermudah proses penelusuran riwayat akreditasi jurnal melalui sistem yang menyimpan SK jurnal terdahulu.

\section{Metode Penelitian}

Tahapan yang digunakan untuk merancang aplikasi ini adalah analisis kebutuhan, perancangan, dan implementasi. Pada perancangan sistem ini tidak terlepas dari bagaimana kebutuhan-kebutuhan tiap pengguna berperan dalam sistem yang akan dibangun, oleh karena itu digambarkan melalui use-case untuk menjabarkan kebutuhan tiap-tiap pengguna dalam sistem informasi jurnal elektronik ini.

Dapat dilihat keterkaitan antar pengguna dilihat pada Gambar 1, dimana terdapat 3 aktor utama yaitu manajemen, guest, dan pengelola. Manajemen disini berlaku sebagai super-admin dimana keseluruhan sistem dapat dilakukan seperti menambah, menghapus, mengubah data jurnal, mencetak data jurnal, dan memperbarui SK jurnal, kemudian pengelola hanya dapat melakukan pengubahan jurnal saja, dan untuk guest hanya mampu melihat data jurnal.

\section{Gambar 1. Use Case Diagram}

Pada tahapan perancangan yang dilakukan adalah perancangan basis data melalui penggambaran basis data secara umum melalui Entity Relationship Diagram (Gambar 2) dimana akan digambarkan entitasentitas utama sistem beserta atribut-atribut di dalamnya. Perancangan basis data juga diimplementasikan dalam bentuk Class Diagram (Gambar 3) yang akan mendefinisikan setiap kelas ke dalam masing-masing atribut pada tabel.

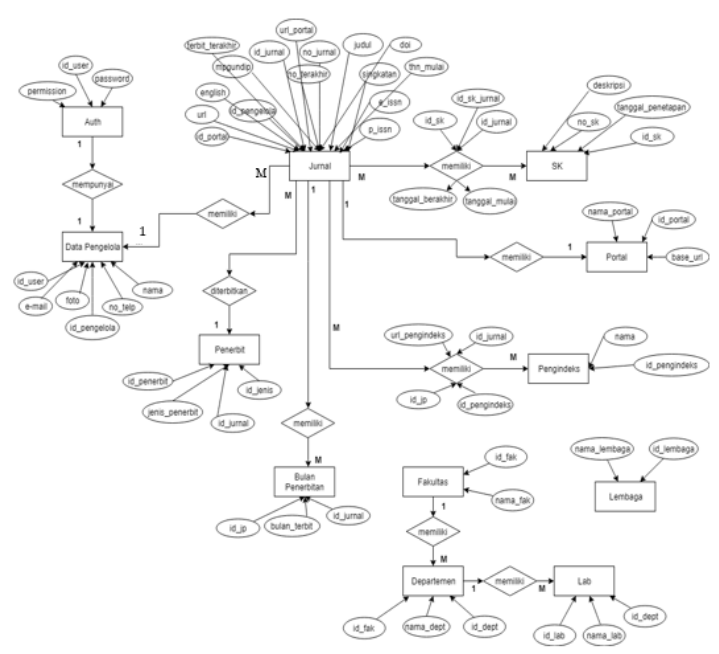

Gambar 2. Entity Relationship Diagram 


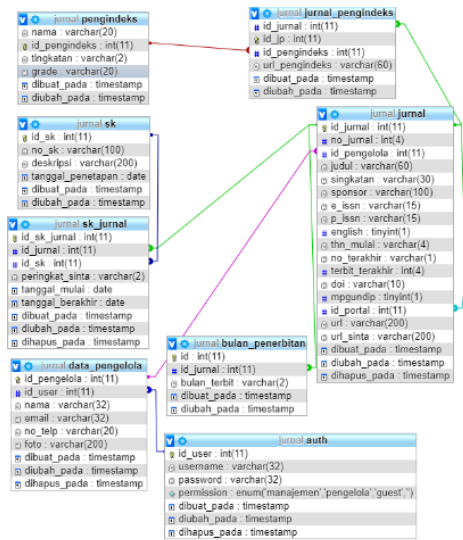

Gambar 3. Class Diagram

Perancangan selanjutnya adalah untuk rancangan antarmuka sistem, dimana akan digambarkan secara umum bagaimana sistem akan diimplementasikan. Gambar 4 menunjukkan halaman guest yang berisi ruang untuk menampilkan informasi umum jurnal serta form login sistem. Gambar 5 menunjukkan halaman manajemen yang berisi pilihan-pilihan menu manajemen dan Gambar 6 berisikan rancangan antarmuka pengelola beserta pilihan-pilihan menu di dalamnya.

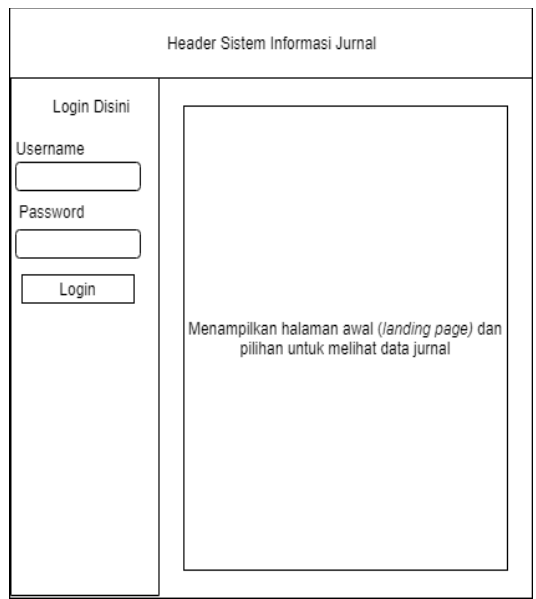

Gambar 4. Rancangan Antarmuka Guest

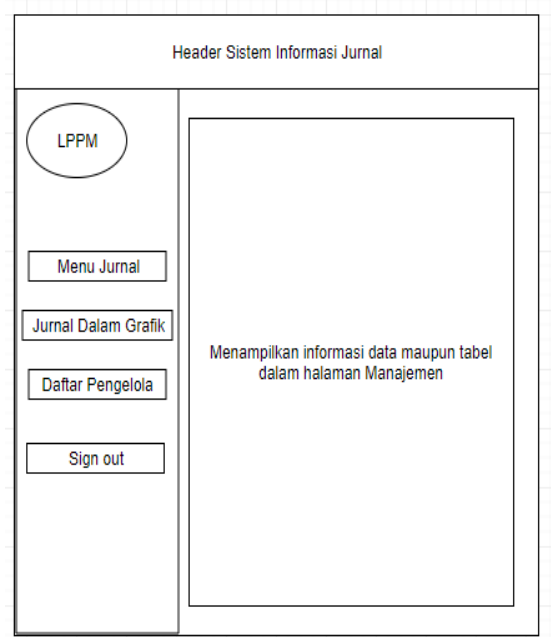

Gambar 5. Rancangan Antarmuka Manajemen

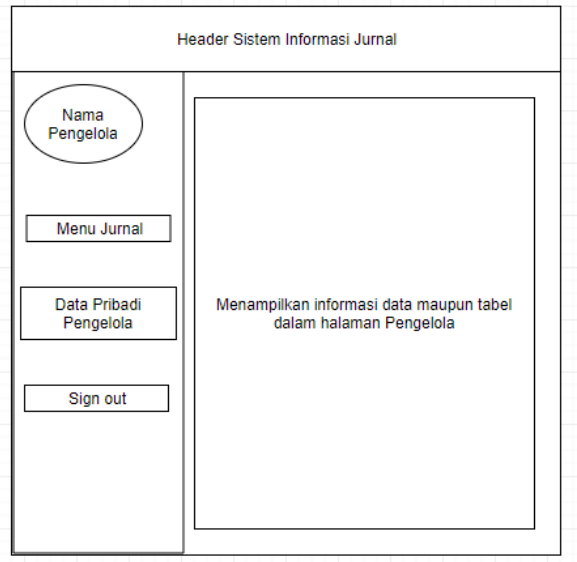

Gambar 5. Rancangan Antarmuka Pengelola

Pada penelitian ini untuk implementasinya nanti, sistem akan diuji menggunakan pengujian black box untuk pengujian fungsi tiap halaman dalam sistem dan pengujian performa untuk menguji kecepatan dan aksesibilitas sistem ketika diakses secara online. Variabel yang diukur dalam pengujian black box adalah kesesuaian fungsi yang dimasukkan dengan keluaran yang diharapkan, sedangkan untuk pengujian performa adalah dengan melihat hasil pengujian per halaman.

\section{Hasil dan Pembahasan}

Berdasarkan apa yang telah dilakukan pada 2 tahapan sebekumnya, yaitu analisis kebutuhan dan perancangan, pada bab ini akan dijabarkan hasil penelitian. Hasil penelitian mencakup apa yang telah ditemukan dari metode yang telah dilakukan dan pengujian terhadap penelitian. Pada Gambar 6 dapat dilihat hasil pembuatan basis data untuk menampung semua tabel pada sistem.

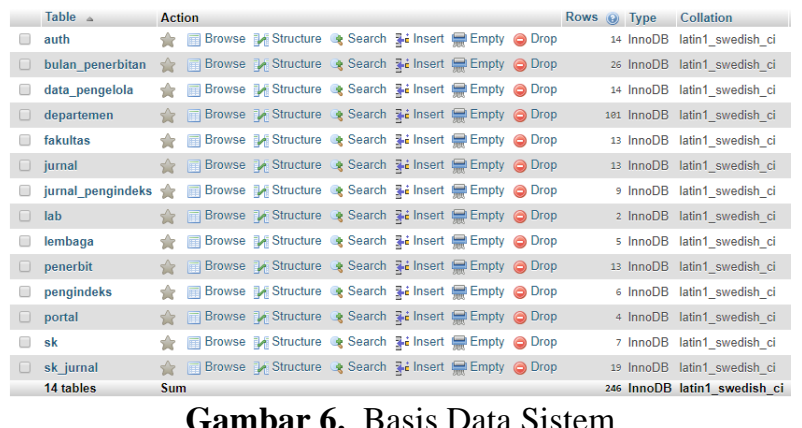

Hasil penelitian selanjutnya adalah sistem yang telah dibuat sesuai dengan perancangan. Pada Gambar 7 dapat dilihat halaman login dan guest yang berisi form login dan informasi singkat jurnal. Pada form login, pengguna di minta memasukkan username dan password. Penggunaan form login ini berguna sebagai keamanan bagi pengguna lain seperti manajemen (LPPM) dan pengelola(ketua editor jurnal) yang ingin masuk ke sistem, sehingga terdapat hak akses yang 
berbeda antara guest, manajemen, dan pengelola. Dalam halaman ini terdapat pula informasi jurnal yang terdaftar dalam sistem dan data jurnal yang disajikan dalam grafik.

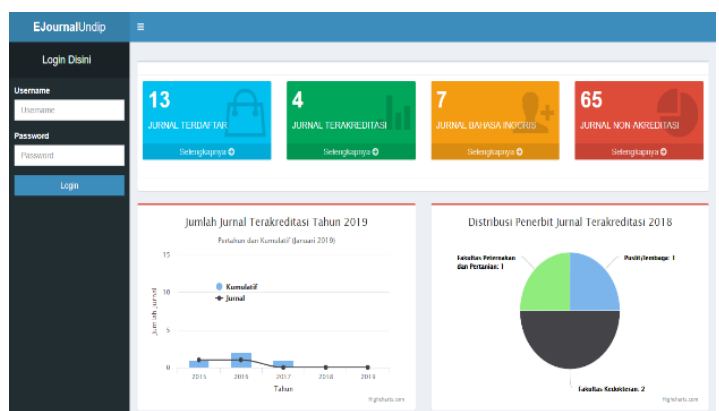

Gambar 6. Halaman Login dan Guest

Gambar 7 merupakan tampilan menu jurnal terdaftar. Pada menu jurnal terdaftar terdapat fitur untuk menambahkan, mengubah, dan menghapus data jurnal. Pada menu ini pula dapat memperbarui sk jurnal, melakukan filter data jurnal hingga mencetak data jurnal dalam bentuk berkas excel dan csv.

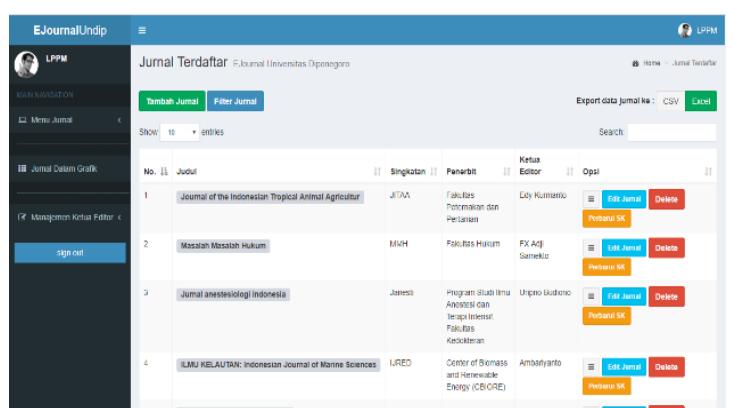

Gambar 7. Halaman Jurnal Terdaftar

Gambar 8 merupakan tampilan form perbarui sk. Pada menu ini manajemen dapat memperbarui sk jurnal, melihat riwayat sk jurnal, dan menghapus riwayat sk jurnal.

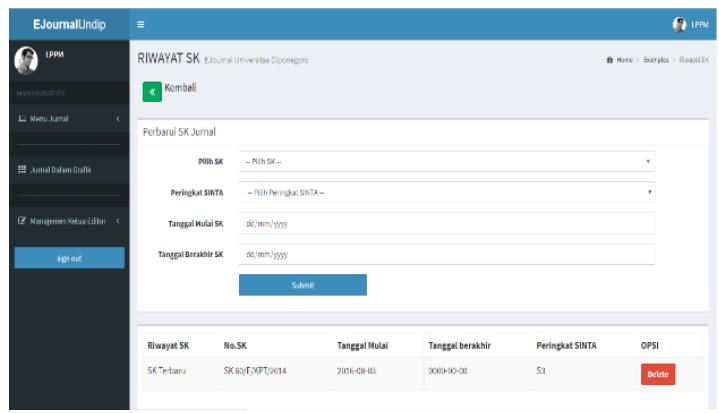

Gambar 8. Halaman Riwayat SK

Gambar 9 merupakan tampilan menu filter data jurnal dan ekspor data jurnal. Menu ini berguna untuk menampilkan jurnal dalam preferensi atau pilihan tertentu, misal menampilkan data jurnal menurut akreditasi, menurut bahasa atau menurut fakultas penerbit. Dalam menu ini sendiri terdapat sembilan preferensi yaitu portal, fakultas penerbit, akreditasi, tahun mulai, bulan terbit, bahasa, indeksasi, DOI, dan E-
ISSN. Pengguna yang telah melakukan pemilihan preferensi, dapat mengklik tombol "Terapkan" untuk melihat data jurnal menurut preferensi yang telah dipilih, kemudian apabila diperlukan data jurnal dapat diekspor menggunakan tombol yang "csv" dan "excel" sesuai keluaran berkas yang diinginkan.

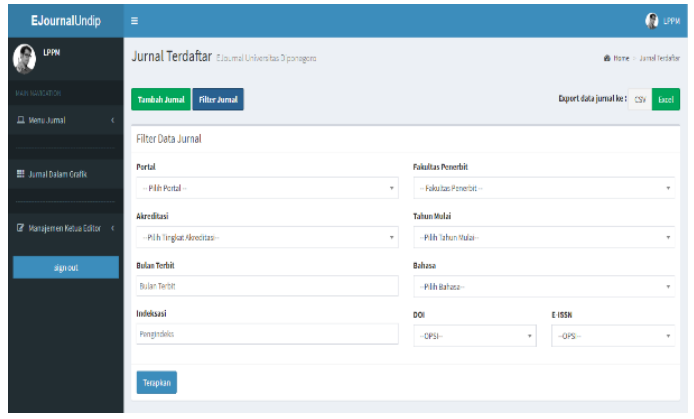

Gambar 9. Halaman Filter Data Jurnal

Gambar 10 merupakan tampilan daftar ketua editor atau pengelola jurnal. Pada tampilan ini manajemen akan diperlihatkan daftar ketua editor jurnal yang terdaftar dalam sistem beserta informasi-informasi penting seperti nomor telepon, $e$-mail maupun foto serta informasi jurnal yang dikelola.

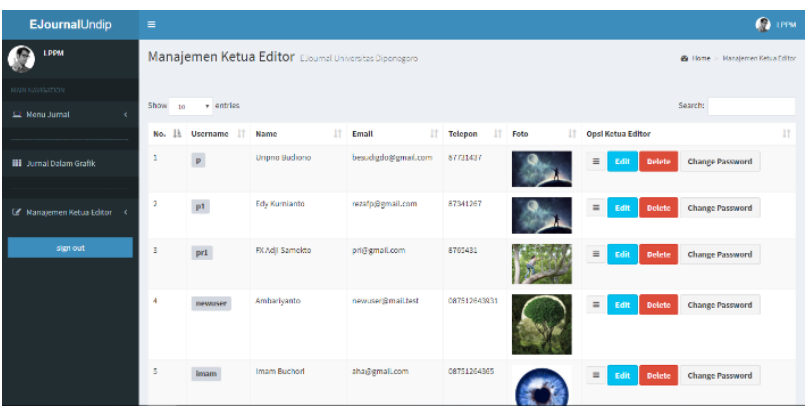

Gambar 10. Halaman Daftar Ketua Editor

Gambar 11 merupakan tampilan pop-up menu detail jurnal. Pada pop-up menu ini dapat dilihat detail data jurnal beserta atribut-atribut dan kelengkapannya. Pada informasi yang memuat link eksternal seperti portal dan url sinta, pengguna dapat mengklik link tersebut untuk kemudian masuk ke halaman yang disediakan oleh link tersebut.

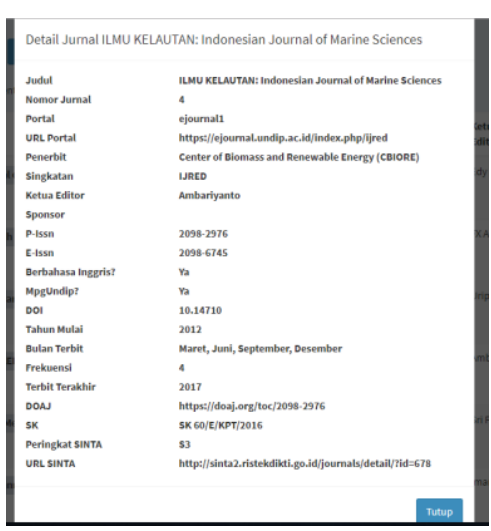

Gambar 11. Detail Jurnal 
Gambar 12 merupakan tampilan daftar departemen. Pada daftar departemen ini dapat dilihat departemen yang terdaftar pada sistem beserta fakultas yang terdaftar pada sistem. Dalam halaman ini terdapat pula pilihan untuk menambahkan departemen, mengubah nama departemen, serta menghapus departemen.

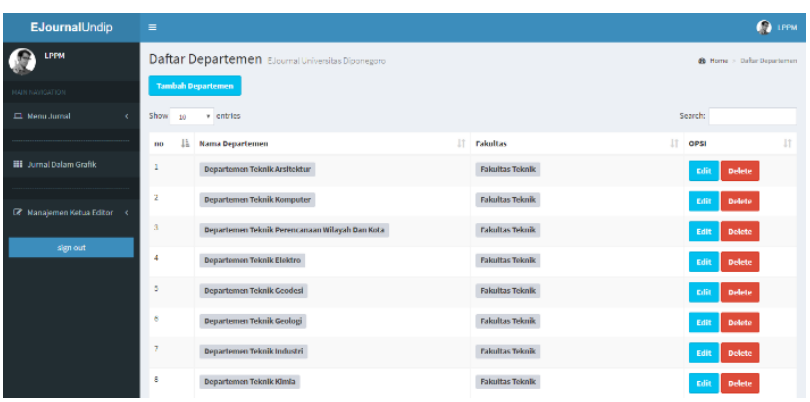

Gambar 12. Halaman Daftar Departemen

Gambar 13 merupakan tampilan daftar sk. Pada tampilan daftar sk ini manajemen akan diperlihatkan daftar sk jurnal yang terdaftar dalam sistem. Dalam halaman ini terdapat pula deskripsi SK, tanggal penetapan SK, serta pilihan untuk menambah, menghapus, dan mengubah data SK.

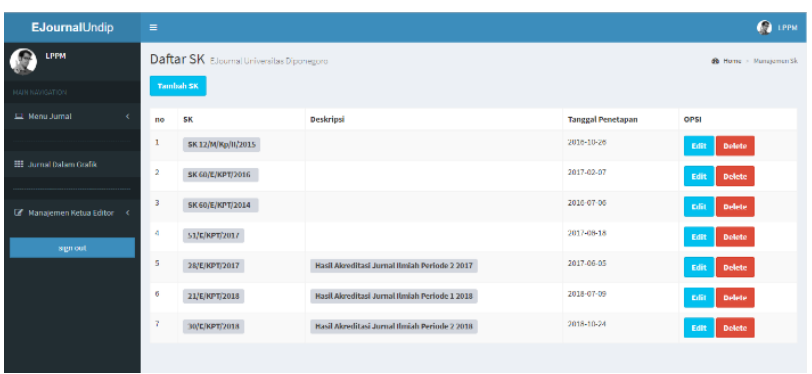

Gambar 13. Halaman Daftar SK

Gambar 14 merupakan tampilan daftar pengindeks. Pada tampilan ini manajemen akan diperlihatkan daftar pengindeks yang terdapat dalam sistem. Dalam halaman ini terdapat pula pilihan untuk menambah, menghapus, dan mengubah data pengindeks.

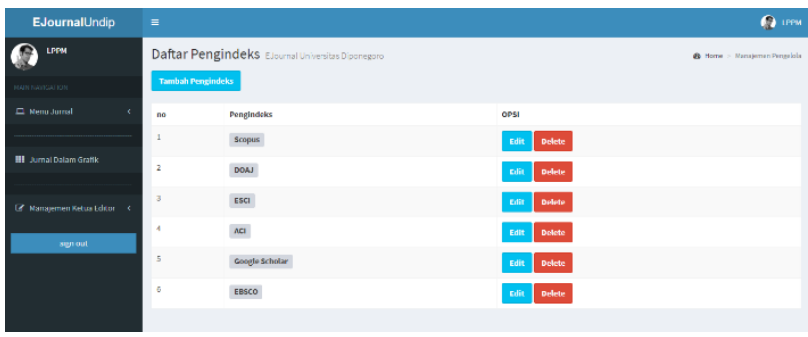

Gambar 14. Halaman Daftar Pengindeks

Gambar 15 merupakan tampilan daftar lembaga. Pada tampilan daftar lembaga ini, pengguna manajemen akan diperlihatkan daftar nama-nama lembaga yang telah terdaftar dalam sistem. Dalam halaman ini terdapat pula pilihan bagi pengguna manajemen untuk dapat menambah, menghapus, dan mengubah data nama lembaga yang telah terdaftar dalam sistem.

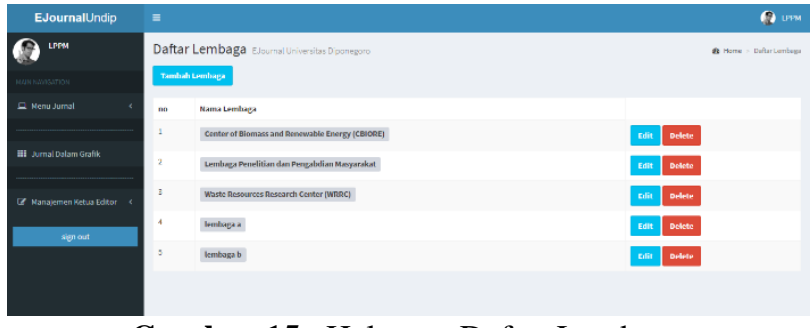

Gambar 15. Halaman Daftar Lembaga

Gambar 16 merupakan tampilan daftar laboratorium. Pada tampilan daftar laboratorium ini manajemen akan diperlihatkan daftar lembaga yang terdaftar dalam sistem. Dalam halaman ini terdapat pula pilihan untuk menambah, menghapus, dan mengubah data laboratorium yang terdaftar dalam sistem.

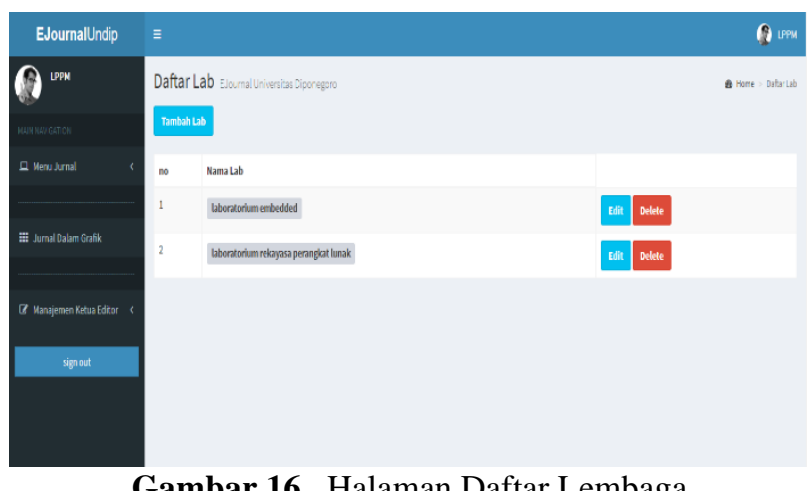

Gambar 17 merupakan tampilan menu untuk masing-masing ketua editor jurnal. Pada menu ini dapat terlihat jurnal yang dikelola oleh ketua editor terkait. Pada menu ini pula ketua editor dapat melakukan pengubahan data jurnal yang dikelola melalui menu edit dan melihat detail jurnal pada tombol yang tersedia.

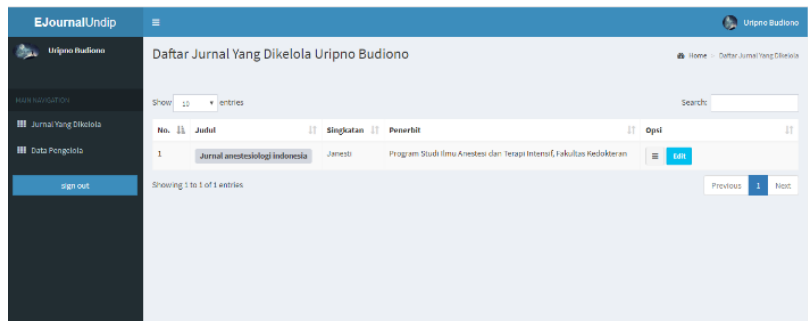

Gambar 17. Halaman Utama Ketua Editor

Pada tahap selanjutnya setelah hasil pembuatan aplikasi maka dilakukan pengujian sebelum aplikasi dipublikasikan. Pengujian pertama dilakukan menggunakan metode black box. Pengujian dilakukan terhadap sistem untuk menilai apakah aplikasi yang diinginkan sudah sesuai dengan yang dirancang atau tidak. 
Tabel 1. Pengujian Fungsional black box

\begin{tabular}{clc}
\hline No. & \multicolumn{1}{c}{ Pengujian Fungsional } & Keterangan \\
\hline $1 . \quad \begin{array}{l}\text { Tersedia halaman utama yang dapat } \\
\text { dilihat oleh manajemen, guest dan } \\
\text { pengelola yang berfungsi sebagai } \\
\text { landing page sistem, berisi selayang } \\
\text { pandang aplikasi . }\end{array}$ & Iya \\
\hline T. & \\
& mersedia halaman Login untuk & \\
terhadap sistem. & Iya \\
\hline 3. & $\begin{array}{l}\text { Tersedia halaman guest, agar guest } \\
\text { dapat melihat data jurnal yang }\end{array}$ & \\
terdaftar beserta detail informasi & Iya \\
jurnal dan data jurnal yang disajikan & \\
dalam bentuk grafik. & \\
\hline Tersedia halaman manajemen, agar \\
manajemen dapat mengelola data \\
jurnal, memperbarui SK jurnal, \\
mencetak data jurnal, serta \\
menampilkan data jurnal sesuai \\
preferensi yang diinginkan melalui \\
menu filter data jurnal.
\end{tabular}

Pengujian selanjutnya merupakan pengujian performansi, dimana pengujian dilakukan menggunakan laman webpagetest.org (Gambar 18). Untuk pengujian performansi, langkah yang dilakukan cukup sederhana yaitu dengan memasukkan $u r l$ halaman yang ingin kita uji, kemudian memilih lokasi uji dan browser yang digunakan. Webpagetest.org kemudian akan memproses dan menganalisa halaman berdasarkan $u r l$ yang telah dimasukkan sebelumnya

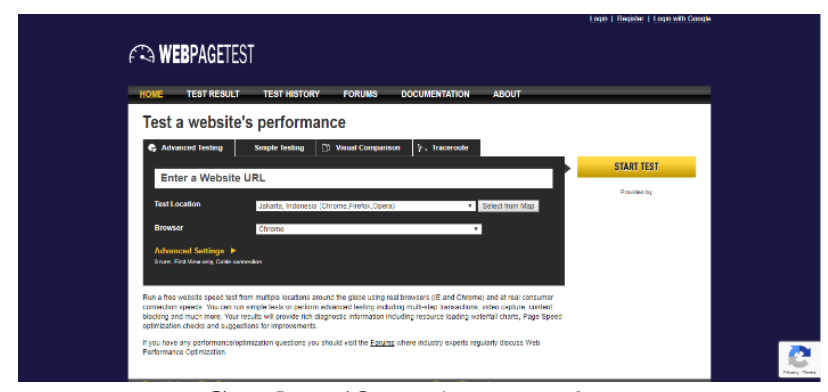

Gambar 18. Halaman webpagetest.org

Terdapat 2 hasil yang dapat diinterpretasikan dan di analisis melalui halaman hasil uji. Pertama, adalah skor performa yang terdapat di pojok kanan atas halaman hasil uji yang ditampilkan melalui huruf. Pada halaman tersebut dapat dilihat 6 skor yang merupakan poin penilaian terdapat halaman yang telah diuji.

First Byte Time adalah waktu yang dibutuhkan ketika pengguna mulai mengakses halaman hingga bit pertama dari respon server tiba, Keep Alive Enabled merupakan kemampuan halaman dalam menjaga koneksi antara konten halaman dengan webserver, Compress transfer dan Compress Images adalah bagaimana halaman mampu mengirim resource dengan tingkat kompresi yang baik sehingga meningkatkan kecepatan konten untuk ditampilkan, kemudian Cache Static Content merupakan tingkat kemampuan halaman untuk menyimpan cache pada kontennya, sedangkan effective use of $c d n$ adalah efektivitas halaman dalam pemakaian Content Distribution Network.

Interpretasi yang kedua adalah melalui tabel hasil performa, terdapat banyak parameter penilaian yang terbagi dalam beberapa kolom. Parameter lain dapat dilihat dari 2 peristiwa yang akan dinilai juga dalam tabel ini, yang pertama adalah peristiwa saat Document Complete yaitu saat dimana pertama kali semua konten tampil pada halaman utama kecuali beberapa perintah javascript dan Fully Loaded yang merupakan peristiwa tampilnya aktivitas-aktivitas javascript setelah halaman utama dapat ditampilkan. Load Time merupakan waktu yang dibutuhkan halaman untuk muncul sampai ke peristiwa Document Complete, First Byte adalah waktu yang dibutuhkan untuk bit pertama webserver sampai ke halaman, kemudian Start Render adalah waktu yang dibutuhkan sejak halaman berwujud blank screen hingga objek pertama dalam halaman muncul.

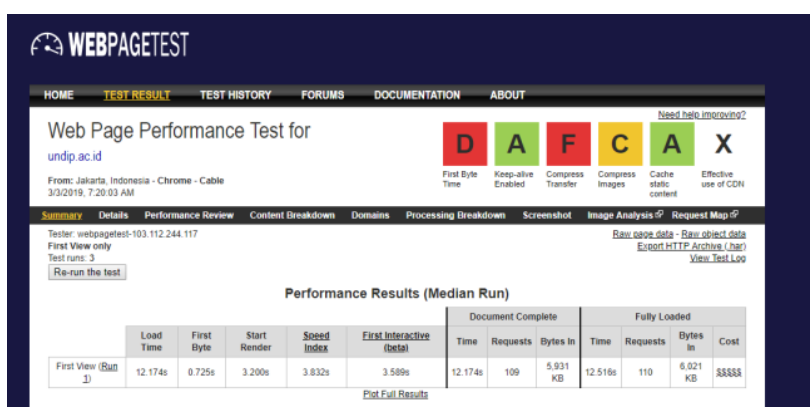

Gambar 19. Contoh Hasil Pengujian Performa

Berdasarkan hasil pengujian performa sistem, dari 27 halaman yang telah diuji, untuk skor First Byte Time hanya 1 halaman mendapat skor $\mathrm{C}$ dan 2 halaman mendapat skor B dan sisanya mendapat skor A yang berarti secara keseluruhan waktu yang dibutuhkan ketika pengguna mulai mengakses halaman hingga bit pertama dari respon server tiba cukup baik. Adapun untuk skor Keep Alive Enabled seluruh 27 halaman mendapat skor A, yang menandakan sistem telah memiliki kemampuan untuk menjaga konektivitas konten dalam sistem dengan webserver dengan sangat baik. Untuk aspek penilaian lain, sistem mendapat performa yang kurang baik, seperti pada Compress Transfer yang dari 27 halaman, 14 diantaranya mendapat skor C, sedangkan sisanya 
mendapat skor B, lalu untuk Compress Image dari 27 halaman, hanya 6 halaman mendapat penilaian A, sisanya tidak mendapat skor atau N/A yang menandakan konten atau resource halaman tidak terkompresi dengan baik sehingga mempengaruhi kecepatan tampilnya halaman. Pada 2 aspek terakhir, yaitu Cache Static Content dan Effective Use of $C D N$, semua halaman sistem mendapat skor $\mathrm{F}$ dan $\mathrm{X}$, yang menandakan bahwa halaman tidak dapat menyimpan cache dengan baik dan tidak menggunakan layanan $\mathrm{CDN}$ pada halaman.

\section{Kesimpulan}

Dari pengujian dan analisa pembuatan sistem informasi jurnal elektronik ini dapat diambil kesimpulan bahwa sistem ini mampu menghimpun dan mengelola data jurnal dan kelengkapannya termasuk data riwayat sk, penerbit jurnal serta pengindeks dan ketua editor jurnal. Sistem ini telah diuji melalui metode black box dan menunjukkan bahwa sistem telah berfungsi sesuai dengan keluaran yang diharapkan. Sistem ini juga telah duji melalui uji performa dan dinyatakan cukup baik dari segi konektivitas konten dengan server dan kecepatan respon server dilihat dari 27 halaman yang telah diuji, hanya 1 halaman yang mendapat skor $\mathrm{C}$.

Saran yang dapat diberikan sebagai upaya pengembangan sistem informasi ini adalah perlu adanya penelitian lanjutan untuk mengembangkan sistem ini agar dapat diintegrasikan dengan sebuah sistem penentuan keputusan klasifikasi jurnal elektronik agar pengelolaan jurnal di Universitas Diponegoro menjadi lebih baik dan efisien. Diperlukan juga adanya pembagian form pada fitur tambah jurnal yang semulanya memasukkan semua data pada satu form, menjadi beberapa langkah input data.

\section{Daftar Pustaka}

[1] Josi, Ahmat., "Perancangan Dan Implementasi EJurnal Pada Unit Penelitian Dan Pengabdian Masyarakat (UP2M) STMIK Prabumulih", Journal of Informatic Pelita Nusantara, Maret 2017.

http://e-

jurnal.pelitanusantara.ac.id/index.php/JIPN/article /view/201.

[2] Aristia Prayudi, Made dkk., "Pengembangan Sistem Informasi Manajemen Pengelolaan Dan Penerbitan Jurnal Ilmiah Jurusan Akuntansi Program S1", Universitas Pendidikan Ganesha , Singaraja, Indonesia, Okt. 2017. http://eproceeding.undiksha.ac.id/index.php/team/ article/view/197

[3] Destiningrum, Mara, and Qadhli Jafar Adrian. "Sistem Informasi Penjadwalan Dokter Berbassis Web Dengan Menggunakan Framework Codeigniter (Studi Kasus: Rumah Sakit Yukum medical centre) "Jurnal Teknoinfo 11.2 (2017): 30-37.

http://ejurnal.teknokrat.ac.id/index.php/teknoinfo/
[4] Sholikhin, Akhmad, and Berliana Kusuma Riasti. "Pembangunan Sistem Informasi Inventarisasi Sekolah Pada Dinas Pendidikan Kabupaten Rembang Berbasis Web." IJNS-Indonesian Journal on Networking and Security 2.2 (2013). http://ijns.org/journal/index.php/ijns/article/view

[5] Gani, Alcianno G. "Analisis Sistem Informasi Pengelolaan Data Alumni Berbasis Codeigniter PHP Framework." JURNAL SISTEM INFORMASI UNIVERSITAS SURYADARMA 5.2 (2018). http://universitassuryadarma.ac.id/journal/index.p $\mathrm{hp} / \mathrm{jsi} /$ article/view/240

[6] Tani, Enjelia, Belinda Begre, and Stenly Adam. "Perancangan Sistem Informasi Kepegawaian PT Sederhana Karya Jaya Berbasis WEB." SENSITEK 1.1 (2018): 368-372.

http://www.sisfotenika.stmikpontianak.ac.id/index .php/sensitek/article/view/340

[7] Siregar, Ratna Aisyah, Ronal Watrianthos, and Marnis Nasution. "SISTEM INFORMASI DATA GURU MDTA PADA KANTOR KESRA SETDAKAB LABUHANBATU BERBASIS WEB." INFORMATIKA 5.2 (2017): 35-45. http://ojs.amik-

labuhanbatu.ac.id/index.php/JIFOR/article/view/8 7

[8] Putra, I. Gusti Agung Sadnyana. "Sistem informasi berbasis web penyediaan trainee dan daily worker untuk industri pariwisata." Matrix: Jurnal Manajemen Teknologi dan Informatika 6.2 (2017): 85.

http://ojs.pnb.ac.id/index.php/matrix/article/view/ 60

[9] Abdullah, Dahlan. "Perancangan Sistem Informasi Pendataan Siswa SMP Islam Swasta Darul Yatama Berbasis Web." IJNS-Indonesian Journal on Networking and Security 4.1 (2015).

http://ijns.org/journal/index.php/ijns/article/view/ 1325

[10] Cahyana, Nur Heri, Bambang Yuwono, and Anjar Yudo Asmoro. "Pengembangan Sistem Informasi Persediaan Barang Berbasis Web di PT. Putera Agung Setia." Seminar Nasional Informatika (SEMNASIF). Vol. 1. No. 4. 2015.

http://jurnal.upnyk.ac.id/index.php/semnasif/articl e/view/1106 